УДК 339.97 JEL H61

Болотин Денис Валерьевич аспирант, ФГБОУ ВО «Государственный университет управления», г. Москва

e-mail:d.v.bolotin@mail.ru

\section{Bolotin Denis}

Postgraduated student, State University of Management, Moscow

e-mail:d.v.bolotin@mail.ru

\section{ТЕНДЕНЦИИ РАЗВИТИЯ РЕГИОНАЛЬНОЙ БЮДЖЕТНОЙ СИСТЕМЫ И БЮДЖЕТНОЙ ПОЛИТИКИ ЕВРОПЕЙСКОГО СОЮЗА НА СОВРЕМЕННОМ ЭТАПЕ}

\begin{abstract}
Аннотация. Предметом исследования в данной статье является бюджетный процесс в Европейском союзе и направления совершенствования бюджетных отношений на наднациональном уровне. Цель исследования - оценка текущих тенденций и проблем развития бюджетных отношений на уровне Европейского союза. Результаты исследования показали, что бюджетная политика Европейского союза существенно трансформировались именно в период 1960-2010 г2. и к настоящему времени именно ее нескоординированность стала одним из барьеров экономического роста стран Европейского союза. В статье проведен анализ основных принципов и проблем реализации бюджетной политики на современном этапе.
\end{abstract}

Ключевые слова: Европейский союз, экономическая интеграция, бюджетная политика, бюджетный прочесс, финансово-экономический кризис.

\section{TENDENCIES OF DEVELOPMENT OF REGIONAL BUDGETARY SYSTEM AND THE BUDGETARY POLICY OF THE EUROPEAN UNION AT THE PRESENT STAGE}

\begin{abstract}
Object of research in this article is the budgetary process in the European Union and the directions of improvement of the budgetary relations at the supranational level. A research objective is assessment of the current tendencies and problems of development of the budgetary relations at the level of the European Union. Results of a research have shown that the budgetary policy of the European Union were significantly transformed to the period of the 19602010 and now its non-coordination became one of barriers of economic growth of EU countries. In article the analysis of the basic principles and problems of realization of the budgetary policy at the present stage is carried out.
\end{abstract}

Keywords: European Union, economic integration, budgetary policy, budgetary process, financial economic crisis.

Под воздействием глобального финансово-экономического кризиса актуализировались проблемы реформирования европейской валютной системы и, вместе с этим, обеспечения стабильности бюджетных отношений, углубления экономической интеграции в бюджетной сфере и укрепления тех институциональных структур, которые способны обеспечить финансовую стабильность в Европейском союзе (далее - ЕС) [6].

Следует учитывать, что европейская валютная система развивается в условиях глобализации мировых финансов и экономики, что подвергает ее риску «заражения» национальных финансовых и экономических систем и риску рецессии, что особенно проявилось в период глобального финансово-экономического кризиса, а также долгового кризиса в еврозоне. С одной стороны, воздействие глобализации привело к обострению проблем, существующих в функционировании экономического и валютного союза. С другой стороны, были сформированы предпосылки для разработки мер активизации процессов интеграции, которые включают в том числе и меры, направленные на консолидацию бюджетной политики и формирование коллективной системы макропруденциального надзора [1]. Можно предположить, что полномочия органов, осуществляющих макропруденциальный надзор, расширятся после того, как начнет функционировать бюджетный союз, так как по ряду вопросов (в частности, запрета на «короткие» продажи) можно принимать лишь рекомендации, не являющиеся обязательными решениями.

Актуальность и значимость исследования бюджетной политики ЕС определяется тем, что в ее рамках правительства стран ЕС собирают налоги и расходуют средства государственных бюджетов с целью обеспечения

(С Болотин Д.В., 2018. Статья доступна по лицензии Creative Commons «Attribution» («Атрибуция») 4.0. всемирная (http://creativecommons.org/licenses/by/4.0/).

The Author(s), 2018. This is an open access article under the CC BY 4.0 license (http://creativecommons.org/licenses/by/4.0/).

(c) (i) 
устойчивых темпов экономического роста (который является краеугольным камнем конкурентоспособности экономики ЕС), реструктуризации национальных экономик за счет инструментов структурной политики либо обеспечения платежеспособного спроса посредством конъюнктурной политики. Важнейшим элементом бюджетной политики является социальная политика, предполагающая качественное совершенствование человеческих ресурсов и масштабное финансирование, здравоохранения и образования.

В настоящее время бюджетная политика ЕС переживает сложный этап трансформации, поскольку современная экономика ЕС уже не выдерживает международной конкуренции и вынуждена искать более совершенную модель социально-экономического развития [4]. После того, как основные рычаги денежно-кредитной политики стран еврозоны перешли на наднациональный уровень, для ЕС в целом актуализировались проблемы координации его экономической и бюджетной политики.

Бюджетная политика ЕС существенно трансформировались именно в период 1960-2010 гг. и к настоящему времени именно ее нескоординированность стала одним из барьеров экономического роста стран ЕС (это, в частности, подтверждается тем, что к 2009 г. в 20 странах ЕС были превышены допустимые пороги бюджетных дефицитов, а в наихудшем положении оказались Греция, Ирландия, Испания и Португалия).

Экономический рост в ЕС на современном этапе относительно невысок и не превышает 2,6 \% в среднем по ЕС. Сохранение невысоких темпов прироста валового внутреннего продукта (далее - ВВП) в подавляющем большинстве стран-членов ЕС было обусловлено понижением макроэкономической активности, что замедлило рост государственного и частного потреблений, инвестиций, способствовало высокому уровню безработицы, устойчивым бюджетным дефицитам и беспрецедентному для стран ЕС уровню государственного долга.

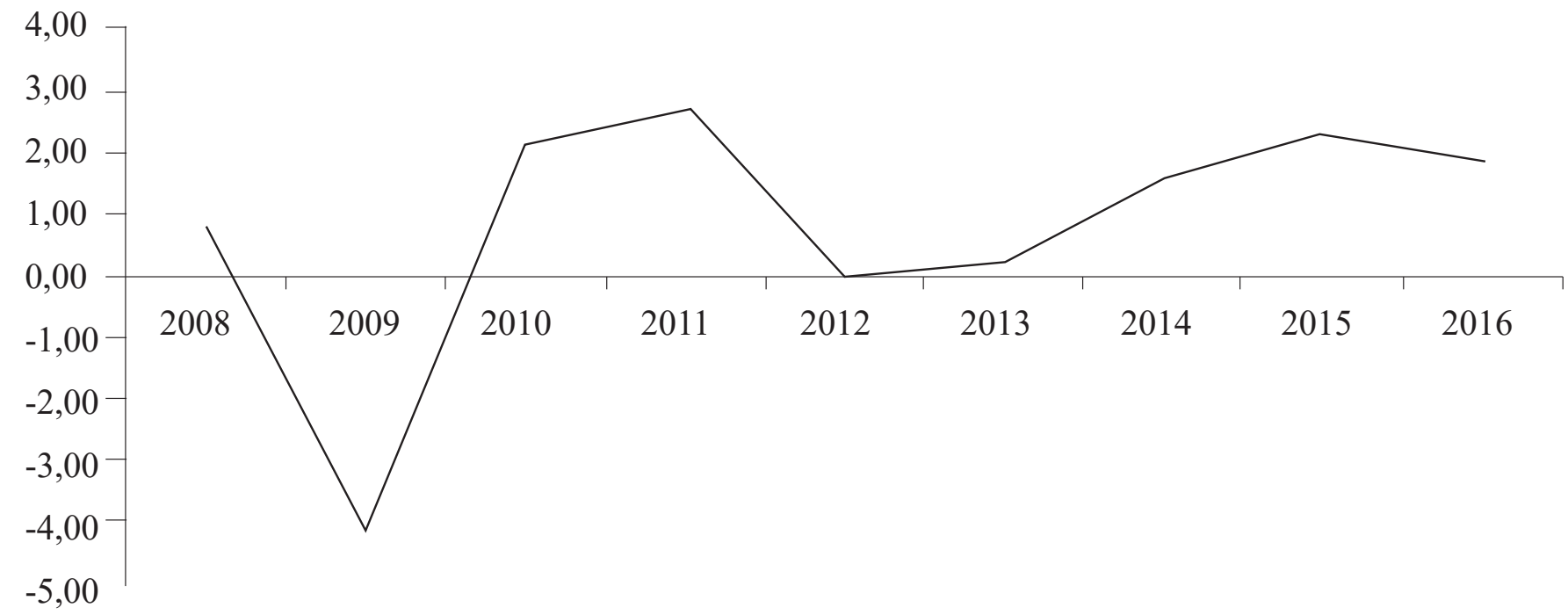

Источник:[8]

Рис. 1. Темпы роста ВВП в Европейском союзе, 2008-2017 гг., \%

Бюджетная политика стала восприниматься эффективным инструментом в сфере управления государственными финансами лишь в 50-60-е гг. прошлого столетия, а до этого в классических моделях социальноэкономического развития данному аспекту уделялось незначительное внимание. Было принято считать, что в результате использования инструментов бюджетной политики активизируется инфляция. Ряд исследований того времени эмпирически доказал и обосновал, что при существовании валютного союза и общей валютной политики отдельными странами - его членами будут учитываться главным образом национальные, а не наднациональные интересы интеграционного объединения [9, с. 445].

По мере эволюции ЕС как интеграционного объединения произошли существенные изменения в структуре и размере его бюджета. Если в 50-е гг. прошлого столетия бюджеты Европейского сообщества по атомной энергии, Европейского экономического сообщества и Европейского объединения угля и стали были нацелена на финансирование главным образом административных расходов, то уже с 1960-х гг. в бюджетах 
европейских сообществ стало обеспечиваться финансирование социальной и аграрной политик. В современных условиях бюджет ЕС в большей степени направлен не на осуществление дотаций (за исключением, пожалуй, аграрной политики), а на реализацию инновационной политики и финансирование структурного выравнивания отдельных регионов [5].

Отметим, что бюджет ЕС стал специфическим инструментом стимулирования стран Европы на их вовлечение в интеграционные процессы. С одной стороны, бюджет ЕС финансирует экономическое развитие стран, не дотягивающих до вхождений в общий рынок, экономический и валютный союзы. С другой же стороны, бюджет ЕС служит способом перехода развитых стран-членов ЕС на более высокие этапы интеграционных процессов, предоставляя им целенаправленные поступления. В итоге бюджет ЕС ориентируется на финансирование приоритетных с коммунитарной точки зрения направлений стратегии развития ЕС.

Очевидно, что следствием постепенного расширения ЕС является рост расходной части общего бюджета, и этот рост также хронически усиливается за счет роста бюрократического аппарата, что также ограничивает разработку эффективного механизма координации бюджетной политики.

После создания валютного союза в ЕС денежно-кредитная политика его членов стала наднациональной, а бюджетная политика оставалась в ведении отдельных стран-членов. Поэтому бюджетная политика ЕС постепенно трансформировалась за счет формирования перераспределительного механизма, внедряя с учетом сохранения социальной ориентации национальных моделей развития ряда стран-членов. Также следует учесть, что бюджет ЕС становился наднациональным в контексте методологии формирования доходов и расходов.

Несмотря на уже сформированный валютный союз, в ЕС в качестве значительного инструмента стабилизации валютной политики выступает не только бюджет. Если учитывать отчисления из ВВП стран ЕС, теоретически исключительное их использование не может выступить механизмом стабилизации, если действуют асимметричные шоки (в частности, потенциально возможное снижение отчислений со стороны отдельных стран при возникновении кризисных ситуаций в них).

В ходе экономической интеграции страны сохранили собственные бюджеты, однако им стала необходимой координация целого комплекса направлений экономической политики, предусмотренных Договором о функционировании ЕС, а ЕС стал нуждаться в некотором инструменте финансовой поддержки на наднациональном уровне в форме общего бюджета [2]. Вместе с тем, ввиду того, что страны не желали передавать большой объем средств на уровень ЕС, его размер стал не большим и до сих пор не превышает $1 \%$ национального дохода стран-членов ЕС [7].

Право ЕС предусматривает построение его бюджета в соответствии с известными принципами бюджетного процесса [10]. Бюджеты стран-членов - второй уровень европейской бюджетной системы, которая не предусматривает внутренних заимствований, и для покрытия дефицитов в бюджетах стран-членов широко применяются внешние заимствования. Также на общеевропейском уровне не предусмотрена единая фискальная политика, а лишь решаются различные вопросы бюджетирования и применение бюджетных ограничений.

После того, как был принят Пакт стабильности и роста, а также меры по уменьшения дефицитов бюджетов ЕС, проявился и ряд других негативных эффектов. К одному из таких эффектов следует отнести так называемый «эффект спилловера», заключающийся в том, что неустойчивость в бюджетной сфере в одной стране может увеличить издержки в прочих странах.

Важнейшими принципами регламентации бюджетной политики стран-членов выступают ограничения бюджетного дефицита (не выше 3 \% ВВП) и государственного долга (он не должен превышать 60 \% ВВП), утвержденные Маастрихтским договором. Позднее Пакт стабильности и экономического роста установил, что бюджетные ограничения будут постоянными требованиями к странам-членам еврозоны [3]. В Пакете были детализированы положения, принятые в Маастрихтском договоре, и установлены принципы бюджетной дисциплины и ее стимулирования, так же как и механизмы реагирования, путем применения защитных мер и установления среднесрочного планирования бюджетов. Таким образом, с момента введения бюджетных ограничений обязательства членов ЕС стали законодательно закреплены. Но страны далеко не всегда соответствовали установленным пороговым значениям бюджетного дефицита, что особенно проявилось в период кризиса. 
Библиографический список

1. Волков, А. М. Тенденции и перспективы развития европейской валютно-экономической интеграции: автореф. дисс. ... канд. экон. наук: 08.00.14 / А. М. Волков. - М., 2012. - 26 с.

2. Мировая экономика и международные экономические отношения: учебник для вузов / под ред. Р. К. Щенина, В. В. Полякова. - М.: Юрайт, 2014. - 446 с.

3. Протокол о процедуре в отношении чрезмерных дефицитов // Портал «Право ЕС» [Электронный ресурс]. - Режим доступа: http://eulaw.ru/treaties/protoc/12 (дата обращения: 27.10.2018).

4. Смирнов, Е. Н. Противоречия глобального экономического роста, или еще раз об эффективности моделей социальноэкономического развития // ЭКО. - 2015. - № 4 (490). - С. 93-104.

5. Смирнов, Е. Н. Экономика Европейского союза: инновационный аспект развития: монография. - Saarbrucken: LAP LAMBERT, 2013. $-163 \mathrm{c}$.

6. Экономика Европейского союза: учебник / под ред. Р.К. Щенина. - М.: Кнорус, 2012. - 558 с.

7. A Budget for Europe 2020: Part II, SEC (2011), 867 // Commission Staff Working Paper. - Brussels, Juny 29, 2011.

8. 2018 Ereport. Мировая экономика [Электронный ресурс]. - Режим доступа: http://www.ereport.ru/stat.php (дата обращения: 14.10.2018).

9. Beetsma, R. et al. The confidence effects of fiscal consolidations / R. Beetsma, J. Cimadomo, O. Furtuna, M. Giuliodori // ECB Working Paper. - 2015. - № 1770.

10. Council Regulation (EC, Euratom), № 1605/2002 of 25 June 2002 on the Financial Regulation applicable to the general budget of the European Communities [Электронный ресурс]. - Режим доступа: http://eur-lex.europa.eu/legal-content/EN/ TXT/?uri=CELEX\%3A32002R1605 (дата обращения: 12.10.2018).

\section{References}

1. Volkov, A. M. Tendentsii i perspektivy razvitiya evropeiskoi valyutno-ekonomicheskoi integratsii: avtoref. diss. ... kand. ekon. nauk: 08.00.14 [Trends and Prospects of Development of the European Currency Economic Integration]. M., 2012. 26 p.

2. Mirovaya ekonomika i mezhdunarodnye ekonomicheskie otnosheniya: uchebnik dlya vuzov / ed. R. K. Shhenin, V. V. Polyakov [World Economy and International Economic Relations]. M.: Yurait, 2014. 446 p.

3. Protokol o procedure v otnoshenii chrezmernyh defitsitov [The Protocol on the Procedure Concerning Excessive Deficits]. Available at: http://eulaw.ru/treaties/protoc/12 (accessed 27.10.2018).

4. Smirnov E. N. Protivorechiya global'nogo e konomicheskogo rosta, ili eshche raz ob effektivnosti modelei sotsial'no-ekonomicheskogo razvitiya [Contradictions of Global Economic Growth or once again about Efficiency of Models of Social and Economic Development]. EKO [EKO], 2015, I. 4 (490), pp. 93-104.

5. Smirnov E. N. Ekonomika Evropeiskogo soyuza: innovatsionnyi aspekt razvitiya [Economy of the European Union: Innovative Aspect of Development]. Saarbrucken: LAP LAMBERT, 2013. 163 p.

6. Ekonomika Evropeiskogo soyuza. Ed. R. K. Shhenin [Economy of the European Union]. M.: Knorus, 2012, 558 p.

7. A Budget for Europe 2020: Part II, SEC (2011), 867. Commission Staff Working Paper. Brussels, Juny 29, 2011.

8. 2018 Ereport. World economy. Available at: http://www.ereport.ru/stat.php (accessed 14.10.2018).

9. Beetsma R. et al. The confidence effects of fiscal consolidations / R. Beetsma, J. Cimadomo, O. Furtuna, M. Giuliodori. ECB Working Paper, 2015, I. 1770.

10. Council Regulation (EC, Euratom), I. 1605/2002 of 25 June 2002 on the Financial Regulation applicable to the general budget of the European Communities. Available at: http://eur-lex.europa.eu/legal-content/EN/TXT/?uri=CELEX\%3A32002R1605 (accessed 12.10.2018). 